Letrônica, Porto Alegre, v. 7, n. 1, p. 475-489, jan./jun., 2014

\title{
FRONTEIRAS SIMBÓLICAS - ESPACCO DE HIBRIDISMO CULTURAL, UMA LEITURA DE DOIS IRMÃOS, DE MILTON HATOUM
}

\author{
SYMBOLIC BOUNDARIES - SPACE OF CULTURAL HYBRIDISM, \\ A READING OF THE BROTHERS, BY MILTON HATOUM
}

\begin{abstract}
Mariana Jantsch de Souza*
Resumo: Num contexto cultural e social a ideia de fronteira é um desdobramento da ideia de Nação, ambas encaradas como construções discursivas e por isso com implicações simbólicas. A fronteira se constrói a partir da diferença, se molda rente à Alteridade e precisa dela para determinar-se. A fronteira, então, denuncia as tensões entre dois espaços: o dentro e o fora; o Eu e o Outro. Ao mesmo tempo, promove imbricações entre seus pares binários, o que resulta em uma zona híbrida onde ocorre o contato entre os polos separados, espaço em que são postos frente a frente. Partindo dessa ideia de fronteira, o presente artigo objetiva discutir as fronteiras simbólicas observadas no romance Dois Irmãos, de Milton Hatoum. A narrativa problematiza o hibridismo cultural e identitário resultante das zonas de fronteira, evidenciando os confrontos e os fluxos que se verificam no espaço fronteiriço a partir da figura do imigrante e do mestiço. Como sugere Homi Bhabha, neste trabalho as fronteiras são pensadas como pontes que atuam em um movimento de "articulação ambulante, ambivalente". 0 fronteiriço é, portanto, o que se pode chamar de entre-lugar, um interstício. Palavras-chave: Fronteiras simbólicas; Hibridismo; Dois Irmãos.
\end{abstract}

\begin{abstract}
In a cultural and social context the idea of boundary is an unfolding of the idea of Nation, both seen as discursive constructions therefore with symbolic implications. The boundary is built from the difference, it is molded close to the Otherness and needs it to be determined. The boundary, then, denounces the tensions between two spaces: the inside and outside, the Self and the Other. At the same time, it promotes imbrications between its binary pairs, resulting in a hybrid zone where contact occurs between the separated poles, space in which they are put face to face. Based on this idea of border, this article aims to discuss the symbolic boundaries observed in the novel The Brothers, by Milton Hatoum. The narrative questions the cultural and identity hybridism resulting from border areas, showing the confrontations and flows that are verified in the border space from the figure of the immigrant and the mestizo. As Homi Bhabha suggests, in this work the boundaries are conceived as bridges that act in a movement of "ambulatory articulation, ambivalent". The borderline is, therefore, what one might call in-between, an interstice.
\end{abstract}

Keywords: Symbolic Boundaries; Hybridism; The Brothers.

\footnotetext{
* Doutoranda em Letras pela Universidade Católica de Pelotas - UCPel (bolsista Capes). Mestre em Literatura Comparada pela Universidade Federal de Pelotas - UFPel (bolsista Capes). Membro do grupo de pesquisa Estudos Comparados de Literatura, Cultura e História. Membro do Laboratório de Estudos em Análise do Discurso (LEAD) da Universidade Católica de Pelotas - UCPel. Email: marianajsouza@yahoo.com.br.
} 


\title{
1 A dimensão simbólica das fronteiras: considerações preliminares
}

Pensar em fronteira é tratar de limites, demarcações, o que pressupõe o dentro e o fora, o mesmo e o diferente. Tratar de fronteira é discutir a diferença e refletir sobre as formas de lidar com ela. No entanto, a ideia de fronteira que aqui se discute está além do sentido dicionarizado de limite geográfico, de demarcação física de espaços. Os limites observados neste trabalho são de ordem simbólica, delimitam-se no plano cultural e social, estabelecendo os espaços que cada sujeito pode ocupar em relação ao grupo e à cultura. Essas fronteiras determinam, portanto, como os sujeitos podem mover-se no plano cultural e social.

Esta dimensão da fronteira é abordada por Sandra Pesavento, em seu artigo Além das fronteiras (2002). Para Pesavento, as dimensões simbólicas dos limites atuam na representação da realidade, na forma como cada indivíduo vivencia a sociedade, o grupo, a cultura:

\begin{abstract}
Sabemos todos que as fronteiras, antes de serem marcos físicos ou naturais, são sobretudo simbólicas. São marcos, sim, mas sobretudo de referência mental que guiam a percepção da realidade. Neste sentido, são produtos dessa capacidade mágica de representar o mundo por um mundo paralelo de sinais por meio do qual os homens percebem e qualificam a si próprios, ao corpo social, ao espaço e ao próprio tempo. Referimo-nos ao imaginário, este sistema de representações coletivas que atribui significado ao real e que pauta os valores e a conduta. Dessa forma, as fronteiras são, sobretudo, culturais, ou seja, são construções de sentido, fazendo parte do jogo social das representações que estabelece classificações, hierarquias, limites, guiando o olhar e a apreciação sobre o mundo (PESAVENTO, 2002, p. 35-6).
\end{abstract}

A fronteira como fator de representação da realidade produz sentidos culturais que estabelecem limites de ordem hierárquica, classificações sociais que direcionam ou guiam as identidades, a construção das identidades. As fronteiras simbólicas atuam como mediadoras das relações e interconexões entre o Eu e Outro a partir desse jogo de representações e dos sentidos que produz, conforme ressalta Pesavento. Assim, essas fronteiras invisíveis e simbólicas são, em última análise, sentidos culturais, formas de representação da realidade.

O valor essencial a partir do qual a dimensão simbólica da fronteira é moldada é a Alteridade, pois a existência das fronteiras pressupõe uma linha de mão dupla: a fronteira demarca as diferenças ao estabelecer o dentro e o fora e ao mesmo tempo 
precisa dessa diferença para existir, de modo que, se não há diferença, não há fronteira e vice-versa. Assim, a fronteira instala-se num terreno minado de ambivalências e em razão disso é o lugar próprio para o diálogo das diferenças.

Mesmo ao considerar a dimensão territorial e política envolvida na noção de fronteira percebe-se uma implicação simbólica voltada para a formulação das identidades, para as limitações e delimitações entre o Eu e Outro que passam também pelo plano do territorial. Nesse sentido, imprescindível citar Benedidt Anderson com sua comunidade imaginada carregada de fronteiras produtoras do sentimento de pertencimento, um dos pilares das identidades. Sendo assim, abordando a ideia de fronteira como desdobramento da ideia de Nação, alcança-se a dimensão simbólica, pois

mesmo nesta dimensão de abordagem fixada pela territorialidade e pela geopolítica, o conceito de fronteira já avança para os domínios daquela construção simbólica de pertencimento a que chamamos identidade e que corresponde a um marco de referência imaginária que se define pela diferença. Nesta medida, o conceito de fronteira trabalha, necessariamente, com princípios de reconhecimento que envolvem analogias, oposições e correspondências de igualdade, num jogo permanente de interpenetrações e conexões variadas (PESAVENTO, 2002, p. 36).

A fronteira é o limiar dos espaços culturais e sociais, demarca suas portas de entrada, é o local em que ocorre o contato inicial com a cultura, marcando a passagem para o interior de um ambiente cultural. É como o patamar junto a uma porta: local onde ainda não se está de fato dentro do ambiente que a porta encerra, mas também não se está completamente alheio ao espaço resguardado pela porta.

Pensado nesse sentido, o limiar carrega o simbolismo das fronteiras invisíveis, das limitações culturais e sociais aqui discutidas. Segundo Jean Chevalier, em seu Dicionário de símbolos, o limiar "simboliza, ao mesmo tempo, a separação e a possibilidade de aliança, uma união, uma reconciliação. Essa possibilidade se realiza se a pessoa que chegar for acolhida no limiar da porta e introduzida no interior, e desaparece se ela ficar apenas no limiar e ninguém vier recebê-la" (CHEVALIER, 2009, p. 549, grifo nosso).

Sendo assim, o limiar das fronteiras simbólicas permite o acolhimento e a rejeição simultâneos, que ocorrem a todo o momento. Enquanto via de mão dupla que permite diversas possibilidades de trânsitos, a fronteira viabiliza movimentos simultâneos que podem até ser contraditórios: ora os sujeitos são acolhidos, ora são rejeitados pelas mesmas motivações. 
Estar no limiar, habitar a fronteira expõe a vontade de incorporar e incorporar-se à Alteridade, é o desejo de conciliar-se com o diferente: "Ficar no limiar é manifestar um desejo de aderir às regras que regem a casa, mas um desejo que ainda não é completo, definido ou ratificado; rejeitar alguém no limiar de sua casa é renegá-lo, é rejeitar a sua adesão" (CHEVALIER, 2009, p. 549). Desse modo, permanecer no entremeio revela a ânsia por pertencer a dois espaços ao mesmo tempo, mas para isso o preço é alto: sujeitar-se a acolhimentos e rejeições inconstantes, mover-se conforme os limiares permitem.

Ainda sobre o simbolismo mobilizado pela fronteira, Jacques Leenhardt, no artigo Fronteiras, fronteiras culturais e globalização (2002), destaca o deus Hermes como o protetor das fronteiras. A partir das características desse ser mitológico discorre sobre a natureza volúvel e plural das fronteiras:

\footnotetext{
Os limites, com efeito, foram sempre sacralizados, tal como o domínio dos espíritos. Eles também foram sacralizados, como se houvesse dúvida quanto aos homens não serem capazes de lhes assegurar a permanência. [...] 0 deus que protege as fronteiras, Hermes, apresenta características bem particulares. Deus móvel, múltiplo, rompe-muralhas, guardião das portas, bi ou quadricéfalas quando ele é representado nas encruzilhadas, deus dos gonzos das portas, mestre das entradas e guia dos viajantes, testemunha dos acordos, dos contratos, das trevas e dos juramentos, Hermes é, também, um embrulhador de pistas e o condutor das almas aos Infernos. Hermes é o deus das passagens, da ultrapassagem dos limites mesmo quando ele simboliza a permanência delas (LEENHARDT, 2002, p. 29-30, grifo nosso).
}

A fronteira, então, nasce da necessidade de trânsitos, de passagens e ultrapassagens que guia o homem, ser que não se prostra diante de limites, de limiares. Em razão disso, é preciso perceber esse entremeio - a zona de fronteira - como o local em que os fluxos ocorrem, as diferenças se misturam e se produz algo entre o dentro e o fora, posto que o que está na fronteira se sujeita às influências dos dois lados e por isso não é totalmente de dentro, nem totalmente de fora. 0 fronteiriço é o híbrido, o mestiço, aquele que encerra em si a articulação ambivalente entre dois espaços. É, como refere Bhabha, um entre-lugar, um interstício.

A fronteira é o lugar próprio das trocas, das interações, das mobilidades culturais. Vincula-se à ideia de limite, mas ao mesmo tempo agrega as diferenças que separa, ou intenta separar. Existe, originalmente, para impedir o trânsito entre os lados que divide, definindo o que está dentro e o que está fora, mas essa nitidez divisória não existe no local fronteiriço. A fronteira, paradoxalmente, divide e permite a união. 
No entanto, não se pode ignorar a função seletiva que a fronteira assume diante do fluxo que possibilita. É um espaço propício a trocas, misturas, mas isso não significa que qualquer mistura pode ocorrer. A fronteira determina como e em que direção viabilizará movências. Dessa forma, ainda que permita a imbricação, não se pode pensála como um território pacífico, em que os fluxos são calmos e sossegados e que as diferenças convivem afetuosamente. Ao contrário, a fronteira é também o local próprio do embate, do conflito, da discórdia, do choque, da contestação. Este é também o motivo da sua existência.

A fronteira ressalta as diferenças, revela as assimetrias especialmente identitárias, mas simultaneamente atua como espaço para trocas, cruzamento de diferenças e por isso fala-se em entre-lugar, em interstício. É nesse sentido que se pode pensar que "a fronteira produz uma realidade movente, somente apreensível por um olhar em trânsito" (CURY, 2003, p. 12).

Também é nesse sentido que se fala em dimensão simbólica das fronteiras, pois estas apontam para trocas culturais, mesclas identitárias, intercâmbios e fluxos de ordem simbólica e não para o sentido rígido de linha divisória.

A fronteira expõe a necessidade interativa ou a natural mestiçagem que constitui os sujeitos: é o espaço em que se realizam os contágios de todas as ordens, é o local em que os indivíduos são confrontados com a miscelânea que os constitui. A fronteira não permite, portanto, que o indivíduo ignore o fato de que o Outro também o constitui, de que é moldado a partir do Outro e que sua alteridade se entranha nas identidades individuais.

É nesse mesmo sentido que Homi Bhabha tece suas considerações acerca da noção de fronteira e sua importância no contexto pós-colonial e pós-moderno em sua obra O local da cultura (1998). Para ele, a fronteira atua como o espaço para articulações ambivalentes:

A significação mais ampla da condição pós-moderna reside na consciência de que os 'limites' epistemológicos daquelas ideias etnocêntricas são também as fronteiras enunciativas de uma gama de outras vozes e histórias dissonantes, até dissidentes - mulheres, colonizados, grupos minoritários, os portadores de sexualidades policiadas. [...] É nesse sentido que a fronteira se torna o lugar a partir do qual algo começa a se fazer presente em um movimento não dissimilar ao da articulação ambulante, ambivalente, do além que venho traçando: 'Sempre, e sempre de modo diferente, a ponte acompanha os caminhos morosos ou apressados dos homens para lá e para cá, de modo que 
eles possam alcançar outras margens... A ponte reúne enquanto passagem que atravessa' (BHABHA, 1998, p. 23-4, grifo nosso).

Para o estudioso, tudo que é produzido na articulação de diferenças culturais configura um entre-lugar, um espaço de fronteira, e a partir disso Bhabha pensa no que chama de hibridismo cultural. Entretanto, Bhabha destaca que esses entre-lugares suscitam fluxos e também conflitos, não podendo ser lidos como locais pacíficos de trocas amistosas. É preciso considerar a ambivalência que os configura, bem como as implicações de cunho identitário que o contato com o Outro produz:

Os embates de fronteira acerca da diferença cultural têm tanta possibilidade de serem consensuais quanto conflituosos; podem confundir nossas definições de tradição e modernidade, realinhar as fronteiras habituais entre o público e o privado, o alto e o baixo, assim como desafiar as expectativas normativas de desenvolvimento e progresso (BHABHA, 1998, p. 21).

Essa perspectiva intersticial que a fronteira revela aponta para as pluralidades que constituem o sujeito, para o Outro como fator de constituição do Eu. Assim, o problema das fronteiras se destaca na contemporaneidade porque os pilares culturais tradicionais das identidades estão em processo de redefinição, de revisão, vez que a pósmodernidade alerta para as pluralidades que configuram os indivíduos, considerados, então, híbridos.

É essa dinâmica do espaço fronteiriço que se tem em vista ao abordar o romance de Hatoum. A proposta deste breve artigo é examinar as fronteiras simbólicas que permeiam a narrativa Dois irmãos (2000), de Milton Hatoum, e a tornam veículo para a discussão identitária, trazendo consigo as noções de hibridismo apresentada por Homi Bhabha.

A perspectiva adotada para as reflexões aqui expostas leva em conta a movência cultural e social vivida nesse contexto, bem como a miscigenação de culturas e de temporalidades históricas que se verifica na narrativa. Portanto, o cerne da discussão que se trava neste trabalho é a constatação de que a fronteira inevitavelmente produz sujeitos híbridos, mestiços, terceiros em relação aos que ocupam apenas o espaço interno ou o externo, uma vez que "se a fronteira cultural é transito e passagem, que ultrapassa os próprios limites que fixa, ela proporciona o surgimento de algo novo e diferente, possibilitado pela situação exemplar do contato, da mistura, da troca, do hibridismo, da mestiçagem cultural e étnica" (PESAVENTO, 2002, p. 37). 
Neste mesmo sentido, Leenhardt afirma que a condição da fronteira é naturalmente constituir e constituir-se em uma terceira dimensão, esta condição é intrínseca à situação limiar da fronteira:

Ora, o espaço da fronteira, do limes, traz em si uma terceira dimensão, um plano em descompasso que permite apreender o território a partir de um ponto de vista tanto externo quanto interno. A fronteira que procurarei mostrar retomando a definição de limes como caminho entre dois territórios e não pertencendo nem a um nem a outro mas aos dois, abre a perspectiva de um terceiro olhar, nem perdido na singularidade do lugar, na cor local, no genius loci, nem perdido nas brumas da abstração universalizante (LEENHARDT, 2002, p. 30, grifo nosso).

\section{Dois Irmãos: uma trama de fronteiras simbólicas}

Do exposto, observou-se que há várias perspectivas para abordar-se a questão da fronteira. A partir de um ponto de vista interno, temos a fronteira que delimita a congruência do espaço e do grupo, enquanto a perspectiva externa trabalha especialmente para a diferenciação, construindo a imagem tão temida do Outro e encerrando o espaço próprio da Alteridade. Nesse campo minado, há também o meio termo, o entre-lugar. Este espaço de indefinição pode ser observado no romance de Milton Hatoum a partir de dois exemplos do híbrido: o mestiço e o imigrante.

A movência dos espaços fronteiriços é sentida na pele pelo narrador, Nael, na condição de mestiço, e também pelo patriarca Halim, um imigrante libanês. A narrativa articula em sua trama as fronteiras simbólicas dentro da própria família, mostrando que já aí o indivíduo é inserido na ordem social a partir de fronteiras que (de)limitam a existência dos sujeitos no grupo familiar. É, então, a partir da família que a condição de mestiço e de imigrante surge e é problematizada na trama de Milton Hatoum.

Dois Irmãos apresenta a história de uma família de origem libanesa que vive na Manaus dos anos 40. O centro narrativo é, aparentemente, os filhos gêmeos do casal Halim e Zana: Yaqub e Omar. Pela voz do mestiço bastardo Nael, filho da empregada/escrava da casa com um dos homens da família de Zana, a história dos libaneses de Manaus ganha forma. A narração de Nael mostra-se como uma tentativa de desvelar sua origem, descobrir qual desses homens o atrela à família libanesa. Para isso, o jovem percorre os trilhos das memórias familiares, memórias suas e de outros, na 
intenção de recompor os resquícios da família que a desavença dos gêmeos dispersou no passado:

\begin{abstract}
Omissões, lacunas, esquecimento. 0 desejo de esquecer. Mas eu me lembro, sempre tive sede de lembranças, de um passado desconhecido, jogado sei lá em que praia de rio (HATOUM, 2006, p. 67, grifo nosso).

Dessa vez Halim parecia baqueado. Não bebeu, não queria falar. Contava esse e aquele caso, dos gêmeos, de sua vida, de Zana, e eu juntava os cacos dispersos, tentando recompor a tela do passado. Certas coisas a gente não deve contar a ninguém", disse ele, mirando nos meus olhos.Relutou, insistiu no silêncio. Mas para quem ia desabafar? Eu era o seu confidente, bem ou mal era um membro da família, o neto de Halim (HATOUM, 2006, p. 101, grifo nosso).
\end{abstract}

Enriquece a trama a personalidade de uma matriarca dominadora e extremamente amorosa com o chamado caçula de sua prole, Omar. Em contrapartida, há um pai passivo e permissivo diante da esposa, que omite seus desgostos e desagrados com relação à postura da matriarca para sempre atender suas vontades.

Desde a infância dos meninos, a dissonância de tratamento entre o primogênito e o caçula é ressaltada na narrativa. A mãe sempre pronta a oferecer algum privilégio ao seu caçula, e o pai às voltas tentando instalar a igualdade entre os filhos. Um dos eventos mais marcantes e que instala definitivamente a desavença e o desamor entre os irmãos é a briga pela namoradinha de infância, que resultou em um corte no rosto de Yaqub, cuja cicatriz eternizaria o episódio, a discórdia, e põe à flor da pele todas as diferenças.

Neste contexto de tensões familiares e em meio a uma miscelânea de diferenças culturais, raciais e étnicas, as fronteiras se multiplicam e se tornam, inicialmente, arenas de gladiadores, local para o enfrentamento da diferença. Desse embate resulta o híbrido, o pluralismo fronteiriço. 0 filho de todas essas fronteiras é Nael: a personificação da imbricação, do espaço fronteiriço que se constitui com relação ao interno e ao externo, ao dentro e ao fora. Nael é o brasileiro libanês, o amazonense indígena.

Na condição de terceiro, de mestiço, Nael nunca se sente completamente dentro ou completamente fora dessas fronteiras. Sua postura diante da família evidencia seu hibridismo e torna aparentes as fronteiras simbólicas presentes na narrativa: "Isso Domingas me contou. Mas muita coisa do que aconteceu eu mesmo vi, porque enxerguei de fora aquele pequeno mundo. $\operatorname{Sim}$, de fora e às vezes distante. Mas fui o observador desse jogo e presenciei muitas cartadas, até o lance final" (HATOUM, 2006, p. 23, grifo nosso). 
Em alguns momentos, Nael não é tratado como membro da família, em outros, em circunstâncias diferentes, é tratado afetuosamente como se fosse o mais jovem descendente do clã. Nael é o filho da cabocla escrava e por isso também está na condição de serviçal aos olhos de Zana e de Omar, perante os quais é apenas um agregado de segunda classe em relação à família. Em razão disso, diante da presença de Zana e Omar não ultrapassa o posto de empregado e as fronteiras que esta circunstância impõe: não lhe é dado o direito de sentar-se à mesa com a família durante as refeições, ocupa um quartinho pequeno nos fundos da casa, cômodo apartado dos demais recintos, tem obrigações e tarefas a cumprir em obediência às ordens de Zana, como se pode perceber nos trechos citados:

Zana me dizia sem olhar para mim, talvez sem sentir a minha presença, [...] (HATOUM, 2006, p. 9, grifo nosso).

Na velhice que poderia ter sido menos melancólica, ela [Zana] repetiu isso várias vezes a Domingas, sua escrava fiel, e a mim, sem me olhar, sem se importar com a minha presença. Na verdade, para Zana eu só existia como rastro dos filhos dela (HATOUM, 2006, p. 28, grifo nosso).

Era um corre-corre sem fim. Zana inventava mil tarefas por dia, não podia ver um cisco, um inseto nas paredes, no assoalho, nos móveis. A estátua da santa no pequeno altar tinha que ser lustrada todos os dias, e uma vez por semana eu subia à platibanda para limpar os azulejos da fachada (HATOUM, 2006, p. 61, grifo nosso).

Fardado, pronto para sair, a ordem de Zana azarava minha manhã na escola [...] Eu bem que podia fazer essas coisas à tarde, mas ela insistia, teimava. [...] Fazia tudo às pressas, e até hoje me vejo correndo da manhã à noite, louco para descansar, sentar no meu quarto, longe das vozes, das ameaças, das ordens. E havia também Omar. Aí tudo se embrulhava, foi um inferno até o fim. Eu não podia comer à mesa com o Caçula (HATOUM, 2006, p. 65, grifo nosso).

Ela [Zana] aproveitava a ausência de Halim e inventava tarefas pesadas, me fazia trabalhar em dobro, eu mal tinha tempo de ficar com minha mãe. Quantas vezes pensei em fugir! (HATOUM, 2006, p. 66, grifo nosso).

Porém, diante do patriarca Halim e do gêmeo Yaqub, o jovem é alguém da família e por isso digno de carinho e de atenção, sendo sempre tratado afetuosamente. Por isso, e em oposição ao tratamento que lhe é dispensado por Zana e Omar, Nael come a mesma comida que os demais membros da família e pode circular livremente pela casa, desfrutando de uma liberdade maior do que a de um real serviçal:

Mas tu [Nael] podes aprender umas palavrinhas, querido (HATOUM, 2006, p. 39 , grifo nosso).

[Yaqub] Abraçou-me com força, depois recuou e me olhou de frente, examinando minha estatura, observando meu rosto (HATOUM, 2006, p. 89). 
Podia frequentar o interior da casa, sentar no sofá cinzento e nas cadeiras de palha da sala. Era raro eu sentar à mesa com os donos da casa, mas podia comer a comida deles, beber tudo, eles não se importavam. Quando não estava na escola, trabalhava em casa, ajudava na faxina, limpava o quintal, ensacava as folhas secas e consertava a cerca dos fundos. Saía a qualquer hora para fazer compras, tentava poupar minha mãe, que também não parava um minuto (HATOUM, 2006, p. 60, grifo nosso).

Um dia, eu estava almoçando quando ele [Omar] se aproximou e deu a ordem: que eu saísse, fosse comer na cozinha. Halim estava por perto, me disse: "Não, come aí mesmo, essa mesa é de todos nós. O Caçula bufava, depois se vingava de mim" (HATOUM, 2006, p. 65, grifo nosso).

Outro aspecto que marca a condição sui generis de Nael na família revela-se em seu próprio nome, escolhido por Halim:

"Quando tu nasceste", ela [Domingas] disse, seu Halim me ajudou, não quis me tirar da casa... Me prometeu que ias estudar. Tu eras neto dele, não ia te deixar na rua. Ele foi ao teu batismo, só ele me acompanhou. E ainda me pediu para escolher teu nome. Nael, ele me disse, o nome do pai dele. Eu achava um nome estranho, mas ele queria muito, eu deixei... Seu Halim. Parece que a vida se entortou também para ele... Eu sentia que o velho gostava muito de ti (HATOUM, 2006, p.180, grifo nosso).

O fato de Halim ter escolhido o nome do filho de Domingas e ter-lhe dado o nome de seu pai, intensifica o vínculo de Nael com a família e, assim, se revigoram as especulações do jovem sobre suas origens misteriosas. É agarrando-se a esses elementos que Nael tenta inserir-se na família e assumir suas raízes nos dois lados da fronteira que o faz ser um híbrido: um manauara indígena de origens libanesas.

Em virtude da clandestinidade de seus laços com a família libanesa, Nael não tem acesso a partes do passado familiar. Não conhece por inteiro o seu próprio passado, desconhecimento que gerou lacunas, dúvidas e muita especulação para o jovem. É a partir disso que Nael se relaciona com o passado e com as memórias suas e de toda a família. É assim que Nael se relaciona com sua própria identidade: com os pés fincados nos dois lados das fronteiras que habita, sempre como um híbrido. Por isso, busca, quase desesperadamente, angariar as memórias dos outros na expectativa de preencher as lacunas do seu passado (e de sua identidade) ao unir todas as lembranças arrecadadas. Foi assim que aprendeu a ser um excelente observador e se tornou um ouvinte atento. Também assim manteve-se à margem; fez-se um personagem secundário em sua própria trama para não ser notado e não impedir ou atrapalhar o fluxo das memórias e conversas que capturava pela casa. 
Com isso, fica evidente a tensão entre os espaços que Nael ocupa e as fronteiras simbólicas que impedem ou limitam seu trânsito no grupo: não é membro da família, mas também não é apenas um empregado. 0 jovem insere-se num entre-lugar: não está totalmente fora, nem totalmente dentro do clã. São essas fronteiras simbólicas que estabelecem como o filho da cabocla pode portar-se no seio familiar e como pode participar da família.

Por outro lado, a condição de imigrante, também ilustrada na narrativa, revela outros desdobramentos das fronteiras simbólicas. A sorte do imigrante expõe a sua condição intersticial, mostra situações que apenas esse sujeito vivencia: "Estava envelhecido, o Halim: uns setenta e tantos, quase oitenta, nem ele sabia o dia e o ano de seu nascimento. Dizia: 'Nasci no fim do século passado, em algum dia de janeiro... A vantagem é que vou envelhecendo sem saber a minha idade: sina de imigrante"” (HATOUM, 2006, p. 113, grifo nosso).

A vida do imigrante é naturalmente permeada por fronteiras: territoriais, culturais e identitárias. É o sujeito que vive na pele a articulação cultural e social que as fronteiras exigem: de um lado suas tradições e suas origens e de outro a cultura estranha na qual está inserido, que se entranha inevitavelmente em seu ser e produz uma nova configuração identitária.

Halim e Zana são imigrantes libaneses que se estabeleceram em Manaus e aí se enraizaram e construíram sua família. É o patriarca que expõe com maior intensidade a "sina do imigrante". Os dois incorporaram alguns costumes e práticas da cultura local, mas suas origens se manifestam com intensidade no espaço da intimidade: a casa. É na casa que se vive o oriente que o casal carrega consigo na memória e na pele.

A memória é fator que mantém viva a origem, a cultura, os costumes libaneses. É pela força da memória que se pode observar a condição ímpar do imigrante, quando o passado toma conta de Halim e de Zana, no momento em que não conseguem mais controlar a língua que falam. Halim alerta que a língua da velhice é a língua materna, pois neste momento da vida a memória não permite mais o acesso ao português, língua estrangeira que os acolheu, mas que não perdeu o caráter adventício:

Ás vezes ele [Halim] se distraía e falava em árabe. Eu sorria, fazendo-lhe um gesto de incompreensão: "É bonito, mas não sei o que o senhor está dizendo". Ele dava um tapinha na testa, murmurava: "É a velhice, a gente não escolhe a língua na velhice. Mas tu podes aprender umas palavrinhas, querido." (Hatoum, 2006, p. 39, grifo nosso). 
Ela [Zana] me reconheceu, ficou me olhando. Então soprou nomes e palavras em árabe que eu conhecia: a vida, Halim, meus filhos, Omar. Notei no seu rosto o esforço, a força para murmurar uma frase em português, como se a partir daquele momento apenas a língua materna fosse sobreviver. Mas quando Zana procurou minhas mãos, conseguiu balbuciar: Nael... querido... (HATOUM, 2006, p. 189, grifo nosso).

As fronteiras simbólicas, por permitirem fluxos e contágios, revelam essas mesclas. $\mathrm{O}$ imigrante que deixa de ser o Outro quando passa a compor a paisagem local juntamente com os demais nativos é uma das figurações da miscelânea fronteiriça. É isso que se verifica na narrativa, pois Halim, por exemplo, ainda que preserve traços fortes de sua cultura oriental, frequenta os botecos de pau a pique dos becos de Manaus, é compadre dos homens de sua redondeza e frequenta as rodas de conversa como um amazonense qualquer. Esse é o resultado da situação de fronteira que Halim vive, que o torna também um sujeito híbrido:

Eu tinha percorrido os caminhos da Cidade Flutuante nas folgas de domingo. No entanto, Halim conhecia o bairro melhor do que eu; conhecia e era conhecido. Quando vendia além da conta, fechava a loja mais cedo e entrava no trançado de ruelas do bairro agitado. Ia de casa em casa, cumprimentava esse e aquele e sentava à mesa do último boteco, onde tomava uns tragos e comprava peixe fresco dos compadres que chegavam dos lagos (HATOUM, 2006, p. 90, grifo nosso).

Halim agora faz parte da Cidade Flutuante, entranhou-se nesse lugar, nos seus costumes, no seu povo, conciliando as diferenças sem esquecê-las. Mantém, pois, sua condição oriental, continua com o hábito de fumar o velho narguilé, ainda come os pratos da culinária libanesa - agora acompanhados pela culinária manauara -, carrega o nome de origem oriental e transmitiu ao neto e aos filhos essas marcas da origem libanesa também por meio dos nomes, identificação inicial de qualquer sujeito. Foi assim que Halim se conciliou e se concilia constantemente com as diferenças e com o Outro da terra que adotou como sendo sua também, pois esse Outro é amazonense assim como Halim se tornou com o tempo.

São essas duas figurações do híbrido, como resultado da zona fronteiriça, que as fronteiras simbólicas observadas em Dois Irmãos apresentam. Na condição de terceiro, de mestiço, Nael nunca se sente inteiramente dentro ou inteiramente fora das fronteiras que marcam a sua existência na família: está sempre no limiar. Sua postura diante do grupo evidencia seu hibridismo, o que também se reflete na narração do passado familiar. São, portanto, as fronteiras simbólicas estabelecidas dentro da família que 
determinam como o mestiço Nael pode e deve se portar e até onde vai o espaço que lhe cabe no grupo.

\section{Considerações Finais}

Em Dois irmãos o narrador dedica-se a resgatar um passado que, pela sua condição na família, era desconhecido. Arrecadou fragmentos e lembranças esparsas do que um dia foi a família para, com isso, tecer seu discurso e sua história de filho - de filho da casa. É nesse espaço narrativo, e desfazendo as lacunas do passado, que Nael se insere na família, sem perder a condição de híbrido, de mestiço. A identidade do filho de Domingas é elaborada a partir de rupturas desfeitas discursivamente, pois, na condição de terceiro, ele encontra seu espaço ao unir os pedaços dispersos do passado. É o discurso, portanto, o instrumento que permite que o narrador tome posse de seu espaço de filho perante a família. É o discurso o instrumento utilizado para apaziguar todas as fronteiras vividas na família.

Nael sempre ocupou uma posição ambivalente na família; viveu entre dois planos: o de filho/neto e também o de agregado que se insere no grupo na condição de serviçal, como alguém externo. 0 jovem, então, não consegue se sentir completamente da família, sendo esse o principal motivo da narração: estabilizar a posição de Nael perante o grupo. Em razão disso, a perspectiva de observação do narrador é, por natureza, dupla. Assim, as fronteiras simbólicas que acompanharam Nael ao longo da vida se impõem também no momento da narração: definem a perspectiva do narrador e os caminhos memoriais percorridos para tecer a sua narrativa de filho.

Sendo assim, ao retratar a condição intersticial que o imigrante e o mestiço vivem, a narrativa evidencia as fronteiras simbólicas por meio de aspectos culturais marcantes no espaço em que se desenrola a trama. São marcas simbólicas importantes das fronteiras aqui observadas os nomes de origem libanesa dos personagens, a culinária típica do oriente que se mostra como fator de integração, a importância que o restaurante libanês (Biblos) do pai de Zana assume como local de deflagração do amor entre o casal e de início de toda a história que é narrada. As tradições libanesas relativas à religião, ao narguilé, à língua na qual Zana confessa suas mágoas e tristezas em relação às desavenças dos filhos, todos esses elementos reforçam fronteiras e tornam palpáveis 
os limites simbólicos abstratos que se impõem e delimitam os espaços sociais e culturais de cada sujeito.

Todos esses elementos se somam e consolidam limites, revelando a tensão entre os dois mundos apresentados: ocidente e oriente, Brasil e Líbano, Manaus e Líbano. Dessa forma, o que serve como demarcação e reforço de limites ao mesmo tempo é fator de demarcação identitária. Os mesmos elementos atuam em duas vias: o que reforça as fronteiras simbólicas também marca uma identidade e fixa o sujeito num espaço cultural e social, determinando em quais sentidos pode o sujeito mover-se.

As fronteiras simbólicas abordadas nesta leitura do romance de Hatoum são, portanto, uma representação da realidade, são os sentidos que essa representação produz e as limitações sociais que impõe. São as fronteiras invisíveis que impediram Nael de assumir a posição de neto e de filho da casa. São, pois, os sentidos envolvidos na demarcação dos limites sociais e culturais, sentidos que guiam processos identitários e definem os espaços identitários, contribuem para a movência dos sujeitos e das posições identitárias.

O drama identitário e a necessidade de recorrer à memória para preencher os vazios que a ausência de uma origem produz, impedindo a elaboração de uma identidade, são a tônica da narrativa. A origem de Nael encontra-se cindida, porque está marcada pela dualidade dos irmãos e pela ambiguidade das dúvidas que o acompanham: Yaqub ou Omar? 0 discurso é construído com o fim de recompor a história da família e unificar a ambiguidade que atormenta o narrador. Essa unificação do passado, no entanto, resulta não em uma resposta para o questionamento central de Nael, mas na consolidação de um espaço para o jovem, quando consegue estabelecer-se como filho da casa. A dúvida é diluída não com uma resposta, mas com a inserção definitiva de Nael na família.

\section{Referências}

BHABHA, Homi. O local da cultura. Trad. Myriam Ávila, Eliana Lourenço de Lima Reis, Gláucia Renata Gonçalves. Belo Horizonte: Ed. UFMG, 1998.

HATOUM, Milton. Dois irmãos. São Paulo: Companhia das Letras; Cia de Bolso, 2006.

CHEVALIER, Jean; GHEERBRANT, Alain. Dicionário de símbolos. Trad. Vera da Costa e Silva [et. al.] - 24aㅡ ed. Rio de Janeiro: José Olympio, 2009. 
CURY, Maria Zilda Ferreira. Fronteiras da memória na ficção de Milton Hatoum. Revista Letras, n 26 - Língua e Literatura: Limites e Fronteiras. Jan./jun. 2003, p. 11-18.

LEENHARDT, Jacques. Fronteiras, fronteiras culturais e globalização. Trad. Sandra Jatahy Pesavento. In MARTINS, Maria Helena (org.). Fronteiras culturais - Brasil, Uruguai, Argentina. Cotia, São Paulo: Ateliê editorial, 2002, p. 27-34.

PESAVENTO, Sandra Jatahy. Além das fronteiras. In MARTINS, Maria Helena (org.). Fronteiras culturais - Brasil, Uruguai, Argentina. Cotia, SP: Ateliê editorial, 2002, p. 3539.

SOUZA, Lynn Mario T. Menezes de. Hibridismo e tradução cultural em Bhabha. In: ABDALA JR., Benjamin (org.). Margens da cultura: mestiçagem hibridismo e outras misturas. São Paulo: Boitempo, 2004, p. 113-133.

Recebido em março de 2014.

Aceito em junho de 2014. 